\title{
Skill in Epistemology I: Skill and Knowledge
}

\author{
Carlotta Pavese
}

\begin{abstract}
$\underline{\text { Abstract }}$
Knowledge and skill are intimately connected. In this essay, I discuss the question of their relationship and of which (if any) is prior to which in the order of explanation. I review some of the answers that have been given thus far in the literature, with a particular focus on the many foundational issues in epistemology that intersect with the philosophy of skill.
\end{abstract}

\section{Introduction}

Knowledge and skill are intimately connected. Scientists cannot get new knowledge without developing their skills for devising experiments. And skilled artists, scientists, and mathematicians must know a lot about their area of expertise in order to perform skillfully and routinely manifest that knowledge through their skillful performances.

Despite this obvious interrelationship, knowledge and skill have received different treatment in analytic epistemology. While philosophers in this tradition have long been in the business of understanding and defining knowledge, the topic of skill has been marginalized. It is only quite recently that skills have made a powerful entrance in two epistemological debates: the debate on virtue epistemology and the debate on the nature of know how.

In this essay, I discuss the question of the relationship between skill and knowledge (Section §2) and of which (if any) is prior to which in the order of explanation (Section §3), with an eye to highlighting the many foundational issues in epistemology that intersect with the philosophy of skill. In section $\S 3$, I will start discussing the relationship between skill and know how, which will be the main topic of the sequel to this essay.

2 Knowledge, justification, and skill

Reductive virtue epistemology defines knowledge in terms of skill (Zagzebski, 1996; 
Sosa, 2007; Greco, 2010; Kelp, 2011; Pritchard, 2012; Kelp, 2013a; Turri, 2015). For example, Sosa thinks of knowledge as apt performance, where an apt performance is defined as a performance that is successful in virtue of one's skill (Sosa, 1995; Sosa, 2007; Sosa, 2009; Sosa, 2011; Sosa, 2015). To use one of Sosa's famous examples, consider an archer attempting to hit the bullseye. She may succeed by luck, as when, even though unskilled, she gets a favorable gust of wind that guides the arrow to the bullseye; or as when, even though she shoots skillfully, unfavorable weather conditions first divert, then redirect the arrow into the bullseye. In both cases, the performance is successful, but not so in virtue of the agent's skill. Hence, a performance may be successful, even skillful (for it is caused by the skill), without being apt. According to this sort of virtue epistemology, knowledge is just an instance of apt performance - i.e., a performance that is successful in virtue of one's cognitive or perceptual skill.

This definition succeeds in its reductive goals only provided that cognitive and perceptual skills are not themselves best understood in terms of knowledge. ${ }^{1}$ Virtue epistemologists tend to define such skills in terms of dispositions to believe truly (Zagzebski, 1996; Greco, 2010; Pritchard, 2005; Pritchard, 2007; Sosa, 2010). But some have pointed out that it is controversial whether one can understand cognitive skills independently of the concept of knowledge. Millar argues that cognitive and perceptual skills are themselves abilities to know - a sort of ability that is not exercised, or one that is exercised but not manifested, when knowledge is not attained (Millar, 2009). Along similar lines, Miracchi proposes that knowledge is a manifestation of a competence to know, thereby seemingly underwriting the claim that at least cognitive and perceptual skills can be defined in terms of knowledge (Miracchi, 2015). Finally, Stanley and Williamson propose that skill in general (and not just cognitive and perceptual skill) is a sort of disposition to know (Stanley \& Williamson, 2016).

What decides between the view according to which knowledge is skillful performance of some sort - a view that defines knowledge in terms of skill - and a view according to which skills are themselves knowledge or at least definable in terms of

\footnotetext{
${ }^{1}$ I am using the expression 'cognitive skill' to refer to any ability that manifest through some cognitive state, such as belief, or knowledge. Cognitive skill is to be contrasted with non-cognitive skill, which primarily manifests not through cognitive states, but through actions.
} 
knowledge? Virtue epistemologists argue that their analysis of knowledge provides the resources for a satisfactory solution of the Gettier problem - the problem of explaining what Gettiered subjects lack over and above their true and justified beliefs (Gettier, 1963). Suppose skills are dispositions to believe truly and suppose a subject exercises one's skill to believe truly when forming a particular belief. The subject may thereby be justified in so believing, may also succeed in attaining a true belief, and nonetheless fail to know. According to virtue epistemologists, in Gettier cases, subjects' true justified belief is not attained because of their skill - i.e., the exercise of their skill explains the presence of the belief and why the belief is justified, but it does not explain its correctness (Sosa, 2007, pp. 95-96).

Thus, one motivation for defining knowledge in terms of skill and for identifying skill with a disposition to be in an epistemic state that falls short of knowledge is that, by doing so, one may be able to offer an illuminating solution of the Gettier problem. The recent literature has, however, questioned whether an analysis of knowledge as apt belief can account for the full range of Gettier cases. To begin with, barn façade cases are a notoriously thorny problem for virtue epistemology (Lackey, 2007; Pritchard, 2012; Kelp, 2013a): suppose one sees a barn in a county that happens to be replete with fake barns that perceptually look exactly like real barns. On the basis of that perceptual experience, one forms the belief that one is looking at a barn. The belief happens to be true and so in virtue of the exercise of one's perceptual competences, yet intuitively it is not knowledge. ${ }^{2}$

Moreover, some have observed that there seem to be other examples of justified true beliefs that fall short of knowledge that are not straightforward to account in terms of lack of an apt belief. For example, Miracchi proposes the following variant of Chisholm's Gettier case (Chisholm, 1966): Annette sees what appears to be a sheep in the field in front of her, and consequently believes there is a sheep in the field. As a matter of fact, Annette is gazing at a sheep dog. However, there is a sheep in the field; moreover, she

\footnotetext{
${ }^{2}$ Sosa accepts the conclusion that the subject in barn façade county knows that she is looking at a barn (Sosa, 2010); however, Sosa takes the knowledge in question to be animal knowledge (apt belief) rather than reflective knowledge (aptly believing that one aptly believes). According to Sosa, then, our intuitions in this example track the lack of the subject's reflective knowledge. But many find this diagnosis unattractive (Pritchard, 2012; Kelp 2013).
} 
inhabits a region where sheep dogs invariably accompany sheep. Miracchi contends that Annette's belief is true as the result of the exercise of a belief-forming competence. Nonetheless, intuitively, her belief does not amount to knowledge (Miracchi, 2015). ${ }^{3}$

Thus, it is still an open question whether or not virtue epistemology can provide a satisfactory explanation of the full range of Gettier cases. Hence, it is still an open question whether a solution to the Gettier problem should be counted among the theoretical benefits of an analysis of knowledge in terms of skill. ${ }^{4}$ What are, on the other hand, the prospects for understanding skill in terms of knowledge?

A characterization of skill in terms of ability to know (or in terms of a competence to know) is not clearly reductive, for it is easy to read "ability" (and "competence") in terms of skill. A better option is to think of skill as a disposition to know (Stanley \& Williamson, 2016). But also this identification faces some prima facie problems. If we say that every sort of skill is a disposition to know, we must take every skill to primarily manifest in knowledge states, and only secondarily in actions. But if so, then there seems to be an important and commonsensical distinction between cognitive skill (like solving a math problem) and non-cognitive skill (like playing tennis) that this view obliterates.

Now, suppose we restrict the view to the case of cognitive skills. Even in this case, one may object to their identification with dispositions to know on the ground that dispositions to know are not obviously necessary for cognitive skills. Suppose George reliably forms true beliefs about trivia questions but an evil demon makes sure that every time that happens, George is given misleading evidence that his beliefs are incorrect. Because at each occasion his beliefs are not supported by evidence, at each occasion, George fails to know. But although George does not have a disposition to know those answers in those particular cases, he is arguably still skilled at trivia.

In response, one may point out that this sort of cases should be described as ones where the disposition to know is present but is "masked" - in this case by the provision of misleading evidence. On the other hand, the sufficiency of dispositions to know for cognitive skills is also controversial. Consider the skill of solving math problems. On a

\footnotetext{
${ }^{3}$ For even more elaborate cases, see (Summerford, 2000; Baehr, 2006; Miracchi, 2015).

${ }^{4}$ Another prominent attempt to reduce propositional knowledge to skill (and know how) is due to (Hetherington, 2006).
} 
view on which cognitive skills are dispositions to know, it is tempting to identify such cognitive skill with the disposition to know the correct solutions to math problems. But now, suppose one has the disposition to know the correct solution to math problems in virtue of having a disposition to look at and to trust one's smart phone, which has a reliable math app. Clearly, one is not thereby skilled at solving math problems. ${ }^{5}$ That suggests that a persuasive defense of a view of skills as dispositions to know needs to say more about what dispositions count (e.g., how extrinsic the dispositions are allowed to be and what kind of knowledge they need to manifest through).

\section{Skill before knowledge?}

We have looked at virtue epistemological attempts to define knowledge in terms of skill and at one attempt to define skill in terms of knowledge - i.e., in terms of dispositions to know. Another possibility is to think of skill directly in terms of standing propositional knowledge states. I will discuss this sort of view in some detail later in the sequel to this essay.

Whether or not the reductive project of defining skill or knowledge in terms of the other can be accomplished, it remains nonetheless a meaningful and interesting question whether skill or knowledge (as well as other epistemic properties) is prior to the other in the order of explanation, for example, because the possession of one is needed for the possession of the other.

In many cases, a skillful action seems to require knowledge — just like a skillful

\footnotetext{
${ }^{5}$ Maybe the right thing to say in response is, instead, that while the subject in the example may not be skilled at solving math problems, nonetheless the subject does have the skill to solve math problems: having the skill to solve math questions does not amount to being skilled at solving math problems, given how that phrase is normally used. But this response comes with the cost of having to reject a plausible principle linking skill possession and the property of being skilled. The following seems like a plausible principle bridging skill possession and the property of being skilled: one is skilled at $\Phi$-ing relative to a context $c$ just in case one possesses the skill to $\Phi$ to the degree fixed by $c .{ }^{5}$ According to this principle, if one possesses a skill to $\Phi$ but does not count as skilled at $\Phi$-ing (relative to a context), it must be because one does not possess the skill to the right degree. That may be, on a view on which skills are disposition to know, because one's disposition to know is not strong enough or because the knowledge that disposition manifests through is not sufficiently good (relative to some relevant standards). The problem now is that, for any degree at which one might possess that disposition, we may envisage a case like the above smart phone's app case where one is disposed to know (to that degree) the solution to math questions (perhaps because the smart phone's app is reliable to that degree or provides answers that are qualitatively good to that degree) and yet one does not intuitively count as skilled at solving math problems.
} 
radiologist needs plenty of medical knowledge and skillful sailor requires knowledge of the boat, of the sea, and of the best circumstances for sailing. It is tempting, on the basis of these examples, to claim that skillful action is action guided by knowledge, thereby prioritizing knowledge over skills in the order of explanation (Stanley, 2011).

Contra this sort of position, Dickie argues that skill comes before knowledge for it is only by appeal to skill that one can explain the kind of knowledge that a skillful agent manifests through their actions (Dickie, 2012). Compare Robin Hood and the Sheriff of Nottingham, who are both shooting at a willow wand 250 yards away. Robin is an expert archer, while the Sheriff is a poor one. This means, roughly, that when Robin intends to shoot at a target, his intention reliably generates a pattern of behavior that, unless his situation is radically unlucky, will result in success. This is not so for the Sheriff. Now, Dickie points out that it is helpful to explain Robin's skillful shooting in terms of Robin's grasp of a proposition about how to shoot in those circumstances. And that that grasp may well satisfy all the conditions for knowledge: it may be produced reliably, it might involve a doxastic commitment, and so on. However, Dickie argues that that does not mean that skillful actions are therefore guided by knowledge - i.e., that knowledge is prior to skill in the order of explanation. Skillful actions may be guided instead by skill and the knowledge that accompanies skillful actions may just be a manifestation of the skill's guidance.

In fact, Dickie thinks that this latter view - one assigning skill priority over knowledge in the order of explanation - has a significant advantage over a view that assigns knowledge priority over skill. Her argument here relies on the consideration of the 'myriad routes to skill acquisition' (Dickie, 2012, p. 741). Skill can be acquired by inborn talent, mindless repetition, unreflective imitation, hypnosis, induction from past attempts, reflection from first principles, and so on. According to Dickie, the heterogeneity of this list generates an objection to an 'intellectualist' view that thinks of skill in terms of knowledge. For an account of the propositional knowledge that guides our skillful action needs a justification component. And it is natural to explain the justificatory component of the knowledge that guides a skillful action by appeal to skill rather than to evidence of the usual sort. By contrast, it is less clear that a view that explains skill in terms of propositional knowledge has the resources for a distinctively 
practical story about how the skilled $\Phi$-er comes by his or her knowledge that $w$ is a way to $\Phi$. So Dickie concludes that "an intellectualist looking for the justification component of the skilled $\Phi$-er's propositional knowledge is thrown back on the standard array of accounts of how propositional knowledge is justified" (Dickie, 2011, pp. 740-742).

Some might question whether a view that explains skill in terms of propositional knowledge really lacks the resources for a distinctively practical story about how the skilled $\Phi$-er comes by his or her knowledge that $w$ is a way to $\Phi$. Suppose one identifies a skill at $\Phi$-ing with the sort of knowledge about how to $\Phi$ that one manifests through skillful actions of $\Phi$-ing and think of such knowledge as an ability to use information for the purpose of action. On this view, the choice of appropriate means to ends is itself guided by a standing propositional knowledge state - say, a state of knowing what to do when. It is compatible with this view to hold that one cannot be in such a knowledge state without possessing a variety of abilities and capacities - which are pre-conditions for being in that knowledge state (Pavese, 2015b, pp. 16-17). Such abilities and capacities are not themselves skills because 1) in contrast with, for example, Robin Hood's skill at archery, they may not be task-specific and because 2) whereas a skill at $\Phi$-ing characteristically manifests through doings — acts of $\Phi$-ing — such abilities do not characteristically manifest through acts (rather they may manifest through operations that are not acts or in states rather than acts). Hence, on a view that distinguishes between skill and the kind of abilities that make a skill possible, the justificatory component of the relevant knowledge can be explained in terms of those basic and underlying capacities rather than in terms of (standardly conceived) evidence.

The same considerations may be relevant to assess virtue epistemology's appeal to skills for the purpose of blocking the regress of justification (Sosa, 1980; Bonjour \& Sosa, 2003). Virtue epistemologists have pointed out that a convenient way to stop the regress of justification (or evidence) is to appeal to a non-propositional justifier in order to explain the justificatory status of at least some of our beliefs - those most basic and fundamental. Our discussion thus far indicates that it is an open question whether skill, rather than any other sort of mental ability that is not a skill, is needed for that purpose. A satisfactory answer to these questions may require a more sophisticated taxonomy of 
skills and abilities than is available at present. $^{6}$

I sketched a view on which skill is prior to knowledge and one on which knowledge is prior to skill. A third possible route consists in taking neither skill nor knowledge to be prior to the other in the order of explanation and explaining both in terms of something more primitive. One example is a view that takes both skillfulness and knowledge to be susceptible of a modal reduction (Beddor \& Pavese, manuscript). ${ }^{7}$ What are the prospects for a unified modal reduction of skillfulness and knowledge?

According to an influential tradition in epistemology, knowledge requires safety from error: if S knows $p$, then $S$ 's belief that $p$ could not easily have been false. Given a possible-worlds semantics for modals, this amounts to saying that, if $\mathrm{S}$ knows $p$, then in all the nearby possible worlds where $\mathrm{S}$ believes $p, p$ is true. ${ }^{8}$ Safety is the most plausible modal requirement on knowledge. And some even take a definition of knowledge in terms of safe beliefs as a working hypothesis. ${ }^{9}$ By contrast, a performance may be skillful even though unsafe or risky - just like a skillful hitting a home run can be highly risky and a very successful player may succeed at it only one time in nine (Beddor and Pavese, manuscript). Because knowledge seems to require safety while skillful performance does not, some have thought that a unified modal reduction of knowledge and skillfulness is not feasible (Sosa, 2007, pp. 29-31; Pritchard, 2012).

As Beddor \& Pavese argue, however, it would be a mistake to conclude that skillful performance is not subject to a modal condition, or that the project of reducing both skillfulness and knowledge to a unified modal property is doomed (Beddor \& Pavese, manuscript). We might just need to formulate the relevant modal condition differently: for example, we might require, for any performance to count as skillful, that it succeed not in every nearby world but in the sufficiently high percentage of nearby worlds, where the right percentage may be determined by the rate of success at the relevant task that a subject would need to meet in order to qualify as skillful at $\Phi$-ing.

\footnotetext{
${ }^{6}$ A similar reply consists in distinguishing between virtues and skills. See (Zagzebski, 1996) for a clearer distinction between virtues and skills.

7 Beddor \& Pavese, "The modal dimensions of skillfulness and knowledge."

${ }^{8}$ For sympathetic discussions of a safety requirement, see Sosa, 1999; Sosa, 2004; Williamson, 2000; Williamson, 2009; Pritchard, 2005; Lasonen-Aarnio, 2010; Pritchard, 2012; Greco, 2015. For detractors, see Comesaña, 2005; Neta \& Rohrbaugh, 2004; Bogardus, 2014.

${ }^{9}$ For example, see Williamson, 2009.
} 
Call this requirement "modal robustness." Then we can say that, whereas for some tasks, such as hitting a home run, even just success at $9 \%$ of the nearby worlds suffices for the performance to count as skillful, for belief nothing less than $100 \%$ is sufficiently high. In this way, we get safety for belief as a special case of a general modal property - i.e., modal robustness - of performances (Beddor \& Pavese, manuscript).

\section{Skills and Know how}

It is hard to talk about skill without talking about know how. In fact, skill is routinely ascribed through know how ascriptions. Some languages, such as Italian and French, do not even have a designated word for skill distinct from their word for ability or from their word for talent, and they systematically ascribe skill through ascriptions of know how (i.e., through ascriptions which would be translated in English by ascriptions of the form "S knows how to $\Phi ") .{ }^{10}$

Moreover, for many tasks at least, it is intuitive that one cannot be skilled at it without knowing how to perform it. For example, a skilled brain surgeon must know how to perform brain surgery. And I cannot be skilled at using the computer if I do not know how to use it. If so, then being skilled at $\Phi$-ing seems to require knowing how to $\Phi$. Finally, it also seems as if know how entails skill: one does not really know how to swim if one does not have the skill to swim; and one cannot know how to tell apart birds without the skills of a bird watcher. Quite generally, it is a platitude that one has savoir faire, or know how, with respect to a certain task only if one has the skill to perform it.

One might object to the sufficiency of know how for skill on the grounds that it is natural to say things such as "John may know how to make risotto, but I would not say he is skilled at it." But there is a natural explanation of the acceptability of that kind of sentences, which is compatible with the sufficiency of know how for skill. Gradable adjectives such as "skilled" quantify over degrees above a certain threshold - in this case over degrees of skillfulness above a certain threshold. So sentences predicating the adjective "skilled" of a subject $S$ are true only provided that $S$ exceeds a contextually

\footnotetext{
${ }^{10}$ As will be discussed in the sequel to this essay, the relevant ascriptions slightly differ from English ascriptions of know how in that they do not embed an interrogative, but rather an infinitival complement, so their form is "S knows + $\Phi$-ing" rather than "S knows + (interrogative) How to $\Phi . "$
} 
fixed threshold (Kennedy, 2007). If so, we are in position to predict that one may know how to make risotto without counting as skilled at risotto making. That will happen whenever the contextually determined standards for being skilled are sufficiently high. However, note that knowing how to make risotto sufficiently well (relative to contextually determined standards) will entail being skilled at it (relative to the same standards). So, although know how does not strictly speaking entail being skilled, knowing how above a certain qualitative (and contextually fixed) threshold does. ${ }^{11}$

It is therefore not all surprising that skill and know how were identified by Ryle in his criticism of the "Intellectualist legend" (Ryle, 1945; Ryle, 1949). In The Concept of Mind, Ryle uses "know how" and "skill" interchangeably (Ryle, 1949). For example, we are told that "though it is proper to ask for the grounds or reasons for someone's acceptance of a proposition, this question cannot be asked of someone's skills at cards..." and that "skillful is an action that manifests know how" (Ryle, 1949, p. 29). Because plausibly an action is skillful only if it manifests a skill, this textual evidence suggests that Ryle did identify skill and know how. In fact, his view of know how as a complex of dispositions is stated, literally, as the view that skill is a complex of dispositions (Ryle, 1949, p. 33).

Ryle's distinction between know how, on one hand, and propositional knowledge on the other hand has been challenged by so-called intellectualists about knowing how (Ginet, 1975; Stanley \& Williamson, 2001; Snowdon, 2004; Stanley, 2011b; Pavese, 2015a; Pavese, 2015b). According to intellectualism about knowing how, know how is just a species of propositional knowledge. Because Ryle has identified know how and skill, it has been commonly assumed that the Intellectualist attack to a Rylean conception of intelligent action had focused both on know how and on skill. ${ }^{12}$ However, the initial debate on intellectualism about knowing how has not explicitly nor systematically addressed the question of the relation between know how and skill. In their pioneering

\footnotetext{
${ }^{11}$ Glick does argue that know how entails ability (Glick, 2011a) and Hawley argues that ability is to be thought of as counterfactual success (Hawley, 2003). If one embraces the entailment from know how to counterfactual success, one is likely to accept that know how must entail skill. See also Beddor \& Pavese (manuscript, "The Modal Dimensions of Skillfulness and Knowledge").

${ }^{12}$ For example, in her incisive critiques of Stanley, Fridland attributes to Stanley the view that skills are propositional knowledge (Fridland, 2014).
} 
paper defending intellectualism about knowing how, Stanley and Williamson distinguish between know how and abilities (Stanley \& Williamson, 2001, p. 416) but nowhere do they use the word "skill." However, in their joint paper, Stanley and Williamson explicitly reject the view that skills are standing propositional knowledge states (Stanley \& Williamson, 2016). Here, they make clear that while they embrace the view that know how is propositional knowledge, they refuse to think of skill as a standing propositional knowledge state.

This discussion brings us to the question of whether intellectualism about knowing how and intellectualism about skill stand or fall together. I will tackle this issue in the sequel to this essay.

\section{Conclusion}

The debate on skill is still very young and I cannot hope to have covered all the interesting issues about the nature of skill and about the relationship between skill and knowledge. But I hope to have at least shown that many foundational issues in epistemology do happen to intersect with the philosophy of skill. If so, then our understanding of the nature of knowledge, of the problem of the regress of justification, of the relation between know how and propositional knowledge may all depend on achieving a better understanding of what skill is as well as on a more accurate taxonomy of our cognitive and non-cognitive abilities.

\section{$\underline{\text { References }}$}

Baehr J. S. 2006. Character in epistemology. Philosophical Studies 128(3): 479-514. DOI: 10.1007.s11098-004-7483-0

Battaly H. D. 2008. Virtue epistemology. Philosophy Compass 3(4): 639-663. DOI: $10.1111 /$ j.1747-9991.2008.00146.x

Bogardus T. 2014. Knowledge under threat. Philosophy and Phenomenological Research 88.2: 289-313. DOI: 10.1111/j.1933-1592.2011.00564.x

Bonjour L, Sosa E. 2003. Epistemic Justification: Internalism Vs. Externalism, Foundations Vs. Virtues. Blackwell Pub. DOI: 10.1093/mind/113.450.319

Comesaña J. 2005. Unsafe knowledge. Synthese 146: 395-404. DOI: 10.1007.s11229- 
003-6213-7

Dickie I. 2012. Skill before knowledge. Philosophy and Phenomenological Research 85(3): 737-745. DOI: 10.1111/j.1933-1592.2012.00638.x

Fridland E. 2014. They've lost control: Reflections on Skill. Synthese 191(12): 27292750. DOI: $10.1007 / \mathrm{s} 11229-014-0411-8$

Gettier E. 1963. Is justified true belief knowledge? Analysis 23:121-23. DOI: $10.2307 / 3326922$

Greco D. forthcoming Safety, Iteration, and explanation. Philosophical Issues. A Supplement to Nous.

Greco J. 2010. Achieving knowledge: A virtue-theoretic account of epistemic normativity. Hetherington SC. 2006. How to Know (That Knowledge-That is Knowledge-How), in Hetherington S (ed.), Epistemology Futures, edn. 1, Oxford University Press, Oxford, pp. $71-94$.

Kelp C. 2009. Knowledge and Safety. Journal of Philosophical Research 34: 21-31. DOI: 10.5840/jpr_2009_1

Kelp C. 2013. Knowledge: The Safe-Apt View. Australasian Journal of Philosophy 91: 265-78. DOI: $10.1080 / 00048402.2012 .673726$

Kennedy C. 2007. Vagueness and Grammar: The Semantics of Relative and Absolute Gradable Adjectives. Linguistics and Philosophy 30: 1-45. DOI: 10.1007/s10988-0069008-0

Lackey J. 2007. Why We Don't Deserve Credit for Everything We Know. Synthese 157: 345-361. DOI: 10.1007/s11229-006-9044-x

Millar A. 2009. What is it that cognitive abilities are abilities to do? Acta Analitica 24: 223-236. DOI: 10.1007/s12136-009-0062-4

Miracchi L. 2015. Competence to know. Philosophical Studies 172(1): 29-56. DOI 10.1007/s11098-014-0325-9

Neta R, Rohrbaugh G. 2004. Luminosity and the safety of knowledge. Pacific Philosophical Quarterly 85(4): 396-406. DOI: 10.1111/j.1468-01142004.00207.x

Pavese C. 2015a. Knowing a rule. Philosophical Issues. A Supplement to Nous. Volume 25 (1): 165-188, 2015. DOI: 10.1111/phis.12045

Pavese C. 2015b. Practical senses. Philosophers' Imprint, 15(29): 1-25. 
Pritchard D. 2005. Epistemic Luck. Oxford University Press, Oxford.

Pritchard D. 2012. Anti-Luck Virtue Epistemology. Journal of Philosophy 109.3: 247279. DOI: $10.5840 /$ jphil201210939

Ryle G. 1945. Knowing how and knowing that: the presidential address. Proceedings of the Aristotelian Society New Series 46: 1-16.

Ryle G. 1949. The Concept of Mind. Chicago University Press, Chicago.

Snowdon P. 2004. Knowing How and Knowing That: A Distinction Reconsidered.

Proceedings of the Aristotelian Society 104(1): 1-29. DOI: 10.1111/j.00667373.2004.00079.x

Sosa E. 1980. The raft and the pyramid: Coherence versus foundations. Midwest studies in philosophy 5: 3-25.

Sosa E. 1995. How competence matters in epistemology. Philosophical Perspectives 24 (1): 465-475. DOI: $10.1111 / \mathrm{j} .1520-8583.2010 .00200 . \mathrm{x}$

Sosa E. 2007. A Virtue Epistemology: Apt belief and reflective knowledge (vol. 1), Oxford University Press, Oxford.

Sosa E. 2011. Knowing Full Well. Princeton University Press, Princeton, NJ.

Sosa E. 2015. Judgment and Agency. Oxford University Press, Oxford.

Stalnaker R. 1984. Inquiry. Cambridge University Press.

Stanley J. 2011. Know How. Oxford University Press, Oxford.

Stanley J, Williamson T. 2001. Knowing How. Journal of Philosophy 98 (8): 411-444. DOI: $10.2307 / 2678403$

Stanley J, Williamson T. 2016 Skill. Nous Online first: pp. 1-14 DOI: $10.1111 /$ nous.12144

Summerford J. 2000. Virtue epistemology and the Gettier Problem. The Southern Journal of Philosophy 38(2): 343-353. DOI: 10.1111/j.2041-6962.2000.tb00904.x

Williamson T. 2000. Knowledge and Its Limits. Oxford: Oxford University Press.

Williamson T. 2009a. Reply to John Hawthorne and Maria Lasonen-Aarnio. In Greenough P, Pritchard D. (eds.), Williamson on Knowledge. Oxford: Oxford University Press: 313-329.

Williamson T. 2009b. Probability and Danger. The Amherst Lecture in Philosophy 4: 135. 
Zagzebski L. 1996. Virtues of the Mind. Cambridge University Press, Cambridge, UK. 